\title{
М.В. Ходяков
}

\section{АГЕНТУРНАЯ РАБОТА НКВД-МВД \\ В ЛАГЕРЯХ ИНОСТРАННЫХ ВОЕННОПЛЕННЫХ ВЕЛИКОЙ ОТЕЧЕСТВЕННОЙ ВОЙНЫ}

В статье, основанной на архивных материалах, анализируется процесс создания в лагерях НКВД-МВД для иностранных военнопленных агентурно-осведомительной сети. Автор указывает на то, что вербовка агентов из военнопленных началась в лагерях в конце 1930-х годов. Однако особый размах она приобрела после завершения основных сражений войны и поступления в лагеря нескольких миллионов военнопленных. В статье показано, как происходила организация единой системы оперативного учета военнопленных в лагерях и их последующая вербовка, осуществлявшаяся в соответствии с приказами НКВД. Отмечается, что вербовались преимущественно военнопленные, на которых имелись незначительные компрометирующие материалы. Предполагалось их внедрение в государственные, общественно-политические, научные, религиозные, спортивные и другие организации уже в послевоенный период.

Наряду с этим активно практиковалось лагерное осведомление. Работа сотрудников НКВД с агентурой осуществлялась в зонах лагерных отделений, где для этого имелись специальные помещения. Агентурная деятельность позволила выявить тысячи военных преступников и провести открытые судебные процессы. По мнению автора, благодаря разветвленной агентурной сети органы НКВД-МВД получали возможность оперативно реагировать на все реакционные проявления. Агенты информировали лагерное начальство о настроениях узников войны, что позволяло принимать меры по смягчению напряженной обстановки в лагерях и предупреждать готовящиеся побеги. Библиогр. 15 назв.

Ключевые слова: лагеря иностранных военнопленных, НКВД, МВД, агентурная работа.

\section{V. Khodjakov}

\section{INTELLIGENCE WORK OF THE NKVD-MVD IN THE CAMPS FOR FOREIGN PRISONERS OF THE GREAT PATRIOTIC WAR}

The article, based on archival materials, shows the process of creating of intelligence agent network in the camps of the NKVD-MVD for foreign prisoners during the Great Patriotic War. The author points out that the recruitment of agents from POW camps began in the late 1930s. However, it acquired a new intensity after the completion of the major battles of the war, and admission to the camps of several millions of prisoners of war. The article shows how the organization of a unified system of operational records of prisoners of war in the camps and their subsequent recruitment was carried out in accordance with the orders of the NKVD. It is noted that the less compromised prisoners were recruited first. They were supposed to be integrated into public, political, scientific, religious, sports and other organizations in the post-war period.

At the same time, internal camp secret informing was actively practiced. The work with the NKVD informer agents was carried out in the camp areas with special rooms. Secret operations with informer agents helped to reveal thousands of war criminals and to organize open trials. According to the author, due to an extensive network of agents, the NKVD-MVD got the opportunity to respond immediately to all manifestations of reaction. The agents' information on the moods of the prisoners of war allowed the camp authorities to take measures to ease tension in the camps and to prevent preparing escapes. Refs 15.

Keywords: The camps for foreign prisoners, the NKVD, the MVD, intelligence work.

Ходяков Михаил Викторович - доктор исторических наук, профессор, Санкт-Петербургский государственный университет, Российская Федерация, 199034, Санкт-Петербург, Университетская наб., 7-9; m.khodyakov@spbu.ru

Khodjakov Mikhail Viktorovich - Doctor in History, Professor, St. Petersburg State University, 7-9, Universitetskaya nab., St. Petersburg, 199034, Russian Federation; m.khodyakov@spbu.ru

(C) Санкт-Петербургский государственный университет, 2016 
Одним из последствий разгрома фашистских армий в годы Великой Отечественной войны стало создание на территории СССР свыше 500 лагерей и других специальных объектов для военнопленных. Через эту систему до конца 1940-х годов прошло более 4 млн военнопленных и около 300 тыс. интернированных [Военнопленные в СССР 2000, с. 12].

Вопросы изучения оперативной работы в лагерях иностранных военнопленных, оказавшихся на территории Советского Союза, до недавнего времени находились в категории табуированных. Лишь в последнее время исследователи получили возможность приступить к анализу ряда животрепещущих проблем русского плена [Иванов, Колошинская 2014, с. 5-208]. Публикация документальных сборников и облегчение доступа к некоторым архивным материалам позволяют проследить процесс создания в лагерях НКВД агентурно-осведомительной сети. Ее формирование началось еще в предвоенный период. Директивой НКВД СССР от 8 октября 1939 г. предусматривалось создание в лагерях агентуры двух категорий: для проникновения в антисоветские группировки среди военнопленных и для «освещения политических настроений» узников войны [Военнопленные в СССР 2000, c. 727-729].

В годы Великой Отечественной войны и особенно после ее окончания процесс насаждения агентуры в лагерях иностранных военнопленных приобрел особый размах. Уже 21 июня 1943 г. начальник управления НКГБ Ленинградской области комиссар государственной безопасности 3-го ранга П.Н. Кубаткин направил на имя наркома госбезопасности В.Н. Меркулова докладную записку, в которой отмечал, что лагеря военнопленных «не используются как база для организации разведывательной и контрразведывательной работы на территории противника и чекистская работа в лагерях ведется лишь в направлении охраны внутреннего оперативного обслуживания без учета необходимости подготовки закордонной агентуры». Стремясь заложить основы для использования военнопленных на территории иностранных государств в послевоенное время, П.Н.Кубаткин полагал, что практика лагерного осведомления является лишь первым шагом на этом пути. По его мнению, залогом успешной работы военнопленных в будущем станет «закрепление вербовки путем отбора информационно-разведывательных и иных сведений, компрометирующих военнопленного перед властями противника» [Ломагин 2004, с. 88].

Директива НКВД СССР от 7 октября 1943 г. «Об агентурной работе среди военнопленных» предписывала активизировать работу в лагерях, тщательно изучать состав военнопленных, перспективную агентуру не использовать «на внутрилагерной общеосведомительной работе», закрепив ее за квалифицированными оперативными работниками [Военнопленные в СССР 2000, с.729-732]. Одновременно предполагалось осуществлять усиленную вербовку агентуры для внедрения ее в государственные, общественно-политические, научные, религиозные, спортивные и другие организации уже в послевоенный период.

После окончания войны агентурно-осведомительная работа в лагерях военнопленных существенно активизировалась. Директивами от 20 июня, 31 августа, 20 сентября, 22 октября, 3 декабря 1946 г. и целым рядом других приказов и положений предписывалось проводить: а) насаждение агентуры в лагерях, выявление сотрудников СД, гестапо, агентов разведывательных и контрразведывательных 
служб; б) выявление участников контрреволюционных формирований, ставящих целью осуществить диверсию, саботаж, вредительство на объектах работы, устанавливающих «в преступных целях» связи с гражданским населением, готовящих групповые вооруженные побеги; в) установление участников зверств и злодеяний как на территории СССР, так и на территории дружественных нам стран [Справки и докладные записки лагеря № 286, л. 13].

Успешному осуществлению этих задач должна была способствовать правильная организация единой системы оперативного учета военнопленных, складывавшаяся еще в довоенный период. На каждый объект оперативного обслуживания по территориально-производственному признаку в НКВД заводилось литерное дело: в районе - на каждый населенный пункт (сельсовет, крупный колхоз, совхоз, MTC), в городах - на крупные промышленные предприятия, учреждения, вузы, систему однородных учреждений и предприятий (районные и городские отделы народного образования и школы, райземотделы, мелиоративные станции и агрокультурные хозяйства и т. д.). Литерное дело состояло из 6 частей: I - официальные материалы по обслуживаемому объекту, II - агентурно-осведомительная сеть, III - списочный учет антисоветского элемента, IV - информационные материалы, $\mathrm{V}$ - материалы об оперативной работе, VI - различная переписка. Кроме того, по промышленным предприятиям оборонного значения и другим объектам особого обслуживания заводились еще две части дела: VII - материалы противодиверсионной работы и VIII - мобилизационная работа [Квартальные отчеты... л. 1-286].

Таким образом, принимая решение о заведении литерного дела, оперуполномоченный I отделения оперативного отдела лагеря военнопленных фиксировал среди прочих моментов и состояние агентурно-осведомительной сети (план ее насаждения, списки секретных агентов и осведомителей с их кличками ${ }^{1}$, график приема, общие сведения о состоянии сети). План проводимых мероприятий утверждался заместителем начальника управления лагеря по оперативной работе.

В соответствии с приказом НКВД СССР за № 001464 от 1 декабря 1944 г. на каждого оперативного работника лагеря, имеющего на связи агентуру, заводился лицевой счет. В него вносилась вся агентура из числа военнопленных и личного состава лагерей, состоящая на централизованном учете. На вновь завербованную агентуру составлялись алфавитные карточки и карточки по форме 1, куда вносились сведения о военнопленных, замешанных в зверствах на территории СССР, участниках диверсионно-вредительской деятельности, а также симулянтах и членовредителях [Списки военнопленных... л. 171-172].

Система учета военнопленных предусматривала составление на каждого узника войны алфавитных карточек и учетного дела. Последнее объединяло все документы о военнопленном. На его обложке проставлялся номер дела, фамилия, имя, год рождения военнопленного, его социальное происхождение и некоторые другие сведения. Как правило, в личное дело вкладывались опись документов, опросный лист и другие документы, связанные с военнопленным [Военнопленные в СССР 2000, с. 969].

Определяя наличие антисоветского элемента в лагере, оперуполномоченный представлял в документах списки учета, учетные дела и компрометирующие ма-

1 В действительности архивные материалы содержат не только клички лагерных агентов, но также их подлинные имена и фамилии, которые автором в данной публикации не приводятся. 
териалы на лиц, проходящих по списочному учету. При этом на каждого военнопленного, взятого на учет, заводилось учетное дело, которое хранилось в III части литерного дела. Компрометирующие материалы подшивались к соответствующим учетным делам. В том случае, если учетных дел оказывалось много, они могли храниться в отдельной папке при литерном деле.

На военнопленных, замеченных в проведении антисоветской работы, подозреваемых в шпионской деятельности, примыкавших к «контрреволюционным партиям», а также на весь офицерский состав заводились дела-формуляры [Военнопленные в СССР 2000, с. 726].

В отношении враждебно настроенных к Советскому Союзу военнопленных заводились также агентурные дела. Это происходило после рассмотрения оперативным уполномоченным оперативно-чекистского отдела соответствующего лагеря агентурных материалов. Агентурное дело получало конкретное наименование (например, «Звери», «Убийцы», «Поджигатели» и т.д.) и регистрировалось в 8-м отделении оперативно-чекистского отдела управления МВД СССР по делам военнопленных и интернированных. Первая часть агентурного дела содержала постановление по делу, список учета связей, установочные материалы и официальные данные фигурантов дела (послужные списки, анкеты, характеристики, справки, протоколы допросов и т.д.), а также копию обвинительного заключения [Агентурное дело... л. 1-12 об.]. Вторая часть агентурного дела включала в себя агентурные материалы, копии протоколов важнейших показаний и некоторые другие документы.

Фигуранты агентурного дела, как правило, арестовывались и препровождались в тюрьму до вынесения приговора. По материалам агентурного дела заводилось следственное дело, материалы которого в конечном итоге передавались в военный трибунал. Однако вынесением строгого приговора такие процессы заканчивались далеко не всегда. Характерным примером может служить агентурное дело «Гитлеровцы», заведенное 20 августа 1946 г. на группу военнопленных лагеря № 331, обвиненных во вредительстве и саботаже в процессе строительства аэродрома в г. Тарту. Рассмотрев обстоятельства дела, военный трибунал дело прекратил, освободив обвиняемых, так как материалы предварительного расследования на суде не подтвердились. Было установлено, что фигуранты дела ничего общего между собой не имели и враждебной пропагандой и саботажем не занимались [Агентурное дело... л. 27]. Правда, обвиняемым, арестованным в конце сентября 1946 г., пришлось провести в тюрьме г. Тарту почти два года до момента освобождения в июне 1948 г.

Усилиями агентуры выявлялись и подлинные враги Советского Союза - фашисты, участвовавшие в зверствах по отношению к мирному населению и советским военнопленным. В конце 1946 г. на группу немецких военнопленных из лагеря № 135 (поселок Ахтме в Эстонии) были заведены учетные дела. Агенты доносили, что некоторые из военнопленных в годы войны были активными участниками расправ с советскими гражданами. Так, например, был выявлен бывший обер-ефрейтор В.Шмидт, который на допросе показал, что в годы войны выполнял функции надзирателя в лагере советских военнопленных. При этом он лично расстрелял «примерно 150 человек военнопленных», которые уклонялись от работы, падали от усталости или были дерзки по отношению к нему. Еще «примерно 40-50 во- 
еннопленных» он уничтожил, привязывая раздетых в холодное время к колючей проволоке и обливая их водой. Кроме того, он практиковал способ уничтожения военнопленных, оставляя их без пищи в глубокой яме, опутанной колючей проволокой. Таким образом, он уничтожил еще «примерно 50-60 военнопленных» [Списки военнопленных... л. 190].

При выбытии военнопленных в другие лагеря учетные дела, дела-формуляры, а также личные дела агентов (осведомителей) особыми отделениями пересылались в орган НКВД по месту убытия военнопленных. При ликвидации особых отделений НКВД лагерей военнопленных (или упразднении самих лагерей) агентурнооперативные и учетные материалы передавались для хранения в 1-й спецотдел НКВД по территориальному признаку [Военнопленные в СССР 2000, с. 726-727].

Процесс создания агентурной сети в лагерях был длительным. Так, формирование оперативного отдела и агентурной сети в таллиннском лагере № 286 началось в сентябре 1945 г., т. е. почти через год после появления приказа об образовании лагеря. Перед сотрудниками, многие из которых совершенно не имели опыта и представления о методах оперативно-чекистской работы, были поставлены серьезные задачи. В результате спустя несколько месяцев, к 1 марта 1946 г., в лагере работали 120 агентов из числа военнопленных (часть из них была завербована еще во фронтовых лагерях). Вербовка проводилась в соответствии с приказами НКВД: вербовались преимущественно военнопленные, на которых имелись незначительные компрометирующие материалы «как средства давления при вербовке». Работа с агентурой проводилась в зонах лагерных отделений, где для этого имелись специальные комнаты. Однако уже в начале 1946 г. были зафиксированы случаи, когда вследствие плохой конспирации сотрудников эти «комнаты проваливались». В лагерном отделении № 6 бывший оперуполномоченный в комнате для агентов проводил допросы военнопленных. В результате в лагере быстро стало известно, что это «комната политофицера». В лагерном отделении № 2 оперуполномоченный «необдуманно построил график явок с агентурой». Провал агентуры был предотвращен только в результате экстренно принятых мер. В лагерном отделении № 3 произошла расшифровка агента. Получив задание, агент «Фогель» рассказал о нем разрабатываемому объекту - рассчитывая выяснить, в какой части тот служил, и принимал ли участие в массовых расстрелах советских граждан в г. Гомеле [Справки и докладные записки лагеря № 286, л. 13].

К маю 1946 г. лагерь № 286 насчитывал около 13 тыс. военнопленных, размещенных по 10 лагерным отделениям, из которых 4 находились в Таллине, а остальные - в радиусе 50-150 км от него. Сложность работы с агентами была продиктована тем обстоятельством, что оперативные отделы лагерных отделений были обеспечены кадровым составом лишь на 50 \%. Переводчиков в лагерных отделениях, расположенных на периферии, не было вовсе. Оперативное обслуживание осуществлялось периодическими выездами сотрудников и переводчиков на места. К тому времени в лагере действовали 77 агентов, взятых на централизованный учет, и 33 агента, еще не состоящих на централизованном учете [Справки и докладные записки лагеря № 286, л. 13].

В феврале 1948 г., в момент приема-передачи дел заместителем начальника лагеря № 286 по оперативной работе, агентурно-осведомительная сеть в лагере превысила 200 агентов и осведомителей. Военнопленных в лагере насчитывалось 
9961 человек в 10 лагерных отделениях. Учетных дел передавалось 748, по личному составу было сдано и принято на оперативное обслуживание 397 человек [Материалы приема-сдачи оперативного отдела... л. 3].

В лагере № 287 (г. Валга, ЭССР) на 1 октября 1946 г. действовало 35 агентов (при общей численности военнопленных 2044 человека). Поощрение агентуры производилось продуктами, деньгами и почтовыми карточками для переписки с родственниками [Справки и докладные записки лагеря № 287, л. 79-80].

По данным на четвертый квартал 1946 г., только в лагерях Эстонии действовало 495 агентов из числа военнопленных [Отчеты по военнопленным, л. 3 об.].

В лагере № 135 на 1 января 1947 г. работали 90 агентов из числа немецких военнопленных. Общее количество военнопленных в лагере в тот момент составляло 9561 человек. За период с 1 января по 1 февраля 1947 г. в лагерь прибыли еще 14 агентов, а к 1 января 1948 г. лагерь «обслуживал» уже 151 агент [Переписка по агентуре... л. 2-7, 20].

Очередной этап активизации агентурной работы в лагерях оказался связан с задержкой репатриации военнопленных. Несмотря на то, что еще в марте-апреле 1947 г. в Москве состоялась четвертая сессия Совета министров иностранных дел, в ходе которой министры иностранных дел союзных держав приняли предложение советской делегации о возвращении в Германию всех военнопленных до 31 декабря 1948 г., план репатриации так и не был выработан. В итоге СССР изменил сроки завершения репатриации, а ТАСС опубликовало соответствующие сообщения в газете «Правда» 4 и 30 января 1949 г. Ликвидация лагерей и отправка военнопленных на родину затянулась до конца 1949 г.

Результатом задержки репатриации стал рост антисоветских настроений в лагерях, где содержались узники войны. МВД СССР доносило высшему политическому руководству страны о том, что это дело рук «некоторой части реакционно настроенных военнопленных». Сложившаяся ситуация способствовала усилению политической и агентурно-оперативной работы среди военнопленных. Организаторы и инициаторы «враждебных действий в лагерях» были преданы суду. В целом по стране с декабря 1948 по март 1949 гг. было разоблачено и осуждено 338 военнопленных, в том числе за диверсию и вредительство на производстве - 13, за саботаж - 161 и за злостные нарушения лагерного режима - 164. Враждебные группы военнопленных были выявлены в лагерях Украины (лагерь № 242), Азербайджана (№ 444), Эстонии (№ 286), в Горьковской и Куйбышевской областях Российской Федерации (№ 117 и 234) [Военнопленные в СССР 2000, с. 869-871].

Агентура регулярно доносила лагерному начальству о высказываниях узников войны. Нередко эти характеристики носили нелицеприятный характер, содержали критику советского строя, руководителей СССР и ГДР. Так, военнопленный доктор Арно Юлиус Герман, содержавшийся в 1948 г. в лагере № 286, в беседе с военнопленными заявил: «Эти братья МВД много хуже, чем было наше Гестапо...». Военнопленный Иозеф Гердель высказался столь же определенно: «Если СССР нас не отпустит, то он нарушит свое слово, и я не смогу с доверием отнестись к словам государственных деятелей. Мы так же обмануты, как Гитлером и Риббентропом. Отношение к социализму у меня прежнее». Военнопленный Гюнтер Болт к этому добавил: «Гитлер нам много обещал, но обещания не выполнил. Не думает ли Советский Союз идти по стопам Гитлера...» [Квартальные отчеты... л. 163-164]. 
В таблице представлено изменение численности агентов-военнопленных в лагере № 289 (г. Кохтла-Ярве, Эстонская ССР).

Движение агентуры в лагере № 289 в 1948 г. *

\begin{tabular}{|l|c|c|c|c|c|c|}
\hline Наименование & Состояло на & \multicolumn{2}{|c|}{ Прибыло } & \multicolumn{2}{|c|}{ Убыло } & Состояло на \\
\cline { 3 - 6 } паготделения & $\mathbf{0 1 . 0 7 . 1 9 4 8}$ & Завербовано & Прибыло & Убыло & Исключено & $\mathbf{0 1 . 1 0 . 1 9 4 8}$ \\
\hline Лаготделение 1 & 122 & 1 & 15 & 36 & 4 & 98 \\
Лаготделение 2 & 17 & - & 5 & 2 & - & 20 \\
Лаготделение 3 & 30 & 1 & - & 16 & - & 15 \\
Лаготделение 4 & 12 & - & - & 5 & - & 7 \\
Лаготделение 5 & - & - & 24 & - & - & 24 \\
Спецгоспиталь & 5 & - & 8 & - & - & 13 \\
№ 1011 & 186 & 1 & 52 & 59 & 4 & 177 \\
Итого & & & & & \\
\hline
\end{tabular}

${ }^{*}$ Составлена по: [Докладные записки... л. 139].

Агент «Дитрих», добывавший информацию в лагере № 135, 8 ноября 1948 г. сообщил, что военнопленный Карл Метке, придя в расположение роты после доклада о XXXI годовщине Октябрьской социалистической революции и ответов на заданные вопросы о сроках репатриации на родину, сказал: «Русские с первого же дня нашего плена обманывают нас, они меня снова увидят с винтовкой в руках, тогда я не буду никогда давать пощады, это будет мое отмщение за мои мучения в плену...». Присутствовавший при этом военнопленный Вальтер Писке, в свою очередь, поддержал Метке и добавил: «Мы их всех повесим, ибо другого они ничего не заслуживают...». Ему вторил и Ганс Гензель, заявлявший, по словам агента «Ульрих», что "русских Иванов нужно всех вырезать, где только увидишь» [Квартальные отчеты... л. 137, 159-160].

25 ноября 1948 г. в лагере № 289 в шахте были обнаружены надписи на вагонетках, выжженные карбидными лампами: «Голосуйте за Гитлера (далее нецензурно по адресу вождя СССР), он в этом году нас не отпустит на родину. Гротеволь ${ }^{2}$ нас продал Москве за несколько вагонов крупы и рыбы». И далее: «Бригадиры, командиры рот и батальонов пусть прекращают работу». Причем на некоторых вагонетках была нарисована фашистская свастика, под которой следовала надпись: «Под этим знаменем нам жилось лучше» [Докладные записки... л. 207-209].

В том же лагере в конце 1948 г. отмечались грубые выпады в отношении советских людей [Ходяков 2014, с. 169-181]. По донесению агента «Тыш», повар лагеря из числа военнопленных прямо заявлял: «Русские слишком большие дураки и не могли бы справиться с работой без него». При этом он утверждал, что «настоящий немец никогда не будет работать с русскими, он не забудет, что он пережил в плену и опять настанет час мести для немцев». Тот же агент доносил, что работающие в конторе шахты военнопленные открыто «обзывают русское начальство». Пользуясь тем, что русские не знают немецкого языка, заявляют им в лицо: «Преступники, негодяи, хулиганы, лентяи и т.д.». Советские люди, не понимая смысла этих слов, смеялись. А военнопленные при этом добавляли: «Ах ты преступник, да ты еще

2 Гротеволь Отто (1894-1964) - немецкий политический деятель, сопредседатель Социалистической единой партии Германии (с 1946 г.), премьер-министр ГДР (с 1949 г.). 
смеешься, можно сразу узнать, что ты за негодяй» [Военнопленные лагерного отделения № 6, л. 9].

Одновременно с этим лагерные агенты свидетельствовали, что военнопленные живо интересовались международными событиями. По донесению агента «Фото», военнопленный Отто Эмминг, содержавшийся в лагере № 135, в декабре 1948 г. заявил: «Разве может Гротеволь для нас что-либо сделать хорошее, если он после 1933 года проживал только в России, получая от Советского Союза вагон масла, он продаст за него 50 тысяч человек военнопленных. Русские ругают нацистов, а сами с нами так плохо обращаются, в первую очередь они сами должны хорошо обращаться с военнопленными, а потом уже ругать других, и такое государство, как Советский Союз, называют еще прогрессивным...» [Докладные записки... л. 206].

Военнопленный лагеря № 289 ефрейтор Герман Астнер, по сообщению агента «Олег», был убежден в том, что все известия, которые поступают из советской зоны оккупации Германии, «являются неправильными», а Гротеволь во время своей поездки в Москву «был ненормальным». Военнопленным, по его мнению, могла помочь «только Англия... Я жду этого дня, а все остальное является ложью» [Квартальные отчеты... л. 136].

Анализ содержания перлюстрированной корреспонденции военнопленных и сводки их высказываний, составленные по донесениям лагерных агентов, в целом ряде случаев демонстрировали и более глубокие оценки международной ситуации со стороны узников войны. Так, военнопленный Иозеф Урбаньяк в разговоре с агентом «Хаус» 16 ноября 1948 г. заявил: «Если в этом году не уедем домой, то не уедем домой вообще. На вопрос “Почему?” - Урбаньяк ответил - "Между СССР и Америкой все время будет раскол, это никогда не изменится”». Другой военнопленный лагеря № 286 Ханс Нойфельд в своем высказывании продемонстрировал не только понимание осложнявшихся с каждым днем отношений между бывшими союзниками по антигитлеровской коалиции, но и неприкрытую агрессию: «Русские проклятые собаки, я их не терплю, но недолго осталось ждать, опять начнется война, тогда я пойду добровольцем и еще больше сделаю, тогда я покажу этим собакам...» [Докладные записки... л. 164].

Военнопленный бывшей германской армии Ханс Иохан Борнхаймер из лагеря № 289 в беседе с другими военнопленными 24 октября 1948 г. заявил: «Если русские не отпустят к 31 декабря военнопленных домой, то они потеряют всю симпатию у меня и у других. Я и другие попытаемся уйти сами. Русские на будущий год в это время будут уничтожены американцами...». Карл Хайнц Герман, содержавшийся в том же лагере, заметил: «Русские мне приелись, и если нас не отпустят в Германию к 31 декабря 1948 года, то весной они получат жару от американцев» [Докладные записки... л. 177-178].

В ожидании новой войны пребывали и некоторые другие узники войны. Военнопленный бывшей германской армии Конрад Херман Кутц в узком кругу заключенных лагеря № 289 говорил: «Я привью с колыбели своим детям ненависть к СССР и, пока буду жив, буду ненавидеть это государство. Если будет новая война, я буду сражаться против СССР. Я намерен совершить побег и скрываться в гор. Тарту, где имею много знакомых женщин» [Докладные записки... л. 208].

На протяжении первой половины декабря 1948 г. агентура зафиксировала целый ряд высказываний военнопленных, которые характеризовались как «профа- 
шистские». Так, военнопленный лагеря № 135 Ганс Готфрид Петерс в кругу своих друзей заявил: «Если только начнется война с Россией, то он на стороне американцев и англичан вновь станет с оружием в руках против русских...» [Докладные записки... л. 205].

25 июля 1948 г. в адрес военнопленного Адольфа Клю, содержавшегося в лагере № 286, было направлено письмо из американской зоны оккупации Германии. В письме был сформулирован следующий вопрос: «Когда же наконец вас отпустят, вы уже постарели и поседели у русского, когда же начнется третья мировая война?» [Докладные записки... л. 50]. До адресата письмо не дошло, поскольку было конфисковано органами цензуры.

Одним из важных направлений агентурной работы в лагерях военнопленных являлась «противопобеговая деятельность». Агенты нередко срывали хорошо подготовленные побеги. Так, в лагере № 270 (Новгородская область) военнопленные в начале 1946 г. готовили побег, который должен был сопровождаться разоружением охраны и ограблением склада. Группу заговорщиков возглавлял бывший член фашистской партии Грутьен, который планировал побег из лагеря и возвращение в Германию через Эстонию, на территории которой он рассчитывал использовать ряд местных жителей, враждебно настроенных по отношению к советской власти. Готовясь к побегу, Грутьен обзавелся рекомендательным письмом от бывшего военнослужащего германской армии эстонца Ягер к его родителям, проживающим в Эстонии [Военнопленные в СССР 2000, с.739]. Однако побег был предотвращен благодаря налаженной агентурной работе в среде военнопленных.

Примерно в это же время органы МВД сразу от нескольких агентов лагеря № 286 получили сведения о том, что на электростанции, где работали военнопленные, неизвестный занимается их «вербовкой в банды». В отношении одного из военнопленных по фамилии Суппер прямо сообщалось, что «ему сделано предложение уйти к бандитам». 28 июня 1946 г. агент «Кох» доносил, что военнопленный Суппер планирует совершить побег, твердо решив «уйти в банду, мотивируя это тем, что ему нечего терять». Готовясь к побегу, Суппер достал пистолет и патроны, обзавелся самодельной рацией, компасом и холодным оружием. Вооружиться военнопленному помогла безалаберность хозяйственного отдела, который привлек 8 человек военнопленных «чистить оружие всех систем» без какого-либо надзора. В итоге Суппер получил возможность «выбрать себе хороший немецкий пистолет», спрятать его и беспрепятственно пронести в лагерь [Справки и докладные записки... л. 47].

Анализ добытых агентурных и следственных материалов позволил заместителю начальника лагеря № 286 по оперативной работе капитану И. И. Ленскому сделать вывод о наличии контрреволюционного «подпольного формирования, имеющего связи с банд-повстанчеством и ориентирующегося на кадры военнопленных» [Справки и докладные записки... л. 26-27, 43, 99-102].

По мысли лагерного начальства, для недопущения беспрепятственного общения военнопленных с гражданским населением агентурная сеть, действовавшая в лагерях, должна была «полностью прикрыть все производственные объекты», где охрана узников войны была затруднена. В ряде случаев подобная практика приносила результаты. Только в лагере № 289 за четвертый квартал 1948 г. силами агентуры был предотвращен 31 готовящийся побег [Квартальные отчеты... л. 52-80]. 
Агентурная работа, осуществлявшаяся в лагерях военнопленных, позволила выявить тысячи военных преступников и провести открытые судебные процессы в Сталино, Севастополе, Бобруйске, Чернигове, Полтаве, Витебске, Новгороде, Кишиневе, Гомеле и других городах страны [Колошинская 2002, с. 28-33]. К осени 1949 г. оперативные отделы лагерей военнопленных агентурным и следственным путем собрали компрометирующие сведения на 37 тыс. узников войны, подлежавших привлечению к уголовной ответственности [Военнопленные в СССР 2000, c. 776-777].

Помимо этого, благодаря деятельности разветвленной агентурной сети органы НКВД-МВД получали возможность оперативно реагировать на все реакционные проявления. Организаторы и инициаторы «враждебных действий в лагерях» были преданы суду. Одновременно с этим агенты информировали лагерное начальство о широком спектре настроений узников войны, позволяя принимать меры по смягчению напряженной обстановки в лагерях и предупреждению готовящихся побегов.

\section{Источники и литература}

Агентурное дело «Гитлеровцы» // Государственный архив Эстонии, филиал (ERAF). Ф.7 SM. Оп. 1. Д. 8. Л. 1-27.

Военнопленные в СССР. 1939-1956. Документы и материалы / сост. М. М. Загорулько, С. Г. Сидоров, Т. В. Царевская; под ред. М. М. Загорулько. М.: Логос, 2000. 1120 с.

Военнопленные лагерного отделения № 6 лагеря №135 МВД ЭССР // Государственный архив Эстонии, филиал (ERAF). Ф.13 SM. Оп. 1. Д.38. Л.9.

Докладные записки по агентурно-оперативной работе в лагерях // Государственный архив Эстонии, филиал (ERAF). Ф. 17 SM. Оп. 8. Д. 44. Л. 50-209.

Иванов В. А., Колошинская Н. В. Военный плен и особенности его регулирования во второй половине 1940-х годов: региональный аспект. СПб.: Санкт-Петербургский имени В. Б. Бобкова филиал ГКОУ ВПО «Российская таможенная академия», 2014. 208 с.

Квартальные отчеты о работе ОЧО лагерей // Государственный архив Эстонии, филиал (ERAF). Ф. 17 SМ. Оп. 8. Д. 38. Л. 1-286.

Колошинская Н. В. Дело Г. Ремлингера и других в контексте послевоенных судебных преследований немецких военнопленных // История государства и права. 2002. № 1. С. 28-33.

Ломагин Н. А. Неизвестная блокада. Документы и приложения. Кн. 2. 2-е изд. СПб.: Изд. дом «Нева», 2004. C. 88.

Материалы приема-сдачи оперативного отдела управления лагеря № 286 МВД ЭССР // Государственный архив Эстонии, филиал (ERAF). Ф.9 ASM. Оп. 1. Д.50. Л.3.

Отчеты по военнопленным // Государственный архив Эстонии, филиал (ERAF). Ф.17 SM. Оп. 8. Д. 12. Л. 3 об.

Переписка по агентуре и подучетному элементу ОЧО лагеря № 135 // Государственный архив Эстонии, филиал (ERAF). Ф. 13 SM. Оп. 1. Д. 21. Л. 2-20.

Списки военнопленных-военных преступников и справки об их деятельности // Государственный архив Эстонии, филиал (ERAF). Ф.13 SM. Оп. 1. Д. 20. Л. 171-190.

Справки и докладные записки лагеря № 286 // Государственный архив Эстонии, филиал (ERAF). Ф. 17 SМ. Оп. 8. Д. 7. Л. 26-102.

Справки и докладные записки лагеря № 287 // Государственный архив Эстонии, филиал (ERAF). Ф. 17 SМ. Оп. 8. Д. 8. Л. 79-80.

Ходяков М.В. «Я никогда не стану другом Советского Союза»: настроения иностранных военнопленных в лагерях НКВД-МВД во второй половине 1940-х гг. // Петербургский исторический журнал. 2014. № 1. С. 169-181.

Для цитирования: Ходяков М.В. Агентурная работа НКВД-МВД в лагерях иностранных военнопленных Великой Отечественной войны // Вестн. С.-Петерб. ун-та. Сер. 2. История. 2016. Вып. 2. C. 139-149. DOI: 10.21638/11701/spbu02.2016.211 


\section{References}

Agenturnoe delo "Gitlerovtsy" [Affair intelligence "Nazis"]. Gosudarstvennyi arkhiv Estonii, filial [State Archives of Estonia, branch] (ERAF), f. 7 SM, op. 1, d. 8. (in Russian, unpablished)

Voennoplennye $v$ SSSR. 1939-1956. Dokumenty i materialy [Prisoners of war in the Soviet Union. 19391956. Documents and Materials]. Comp. M.M.Zagorul'ko, S. G.Sidorov, T. V.Tsarevskaia; ed. by M.M.Zagorul'ko. Moscow, Logos Publ., 2000, 1120 p. (in Russian)

Voennoplennye lagernogo otdeleniia № 6 lageria №135 MVD ESSR [Prisoners of war camp camp branch number 6 №135 Ministry of Internal Affairs of the ESSR]. Gosudarstvennyi arkhiv Estonii, filial (ERAF) [State Archives of Estonia, branch], f. 13 SM, op. 1, d. 38. (in Russian, unpablished)

Dokladnye zapiski po agenturno-operativnoi rabote $\mathrm{v}$ lageriakh [Reports of the of agent-operative work in the camps]. Gosudarstvennyi arkhiv Estonii, filial (ERAF) [State Archives of Estonia, branch], f. 17 SM, op. 8, d. 44. (in Russian, unpablished)

Ivanov V.A., Koloshinskaia N.V. Voennyi plen i osobennosti ego regulirovaniia vo vtoroi polovine 1940-kh godov: regional'nyi aspekt [Military captivity and features of its regulation in the second half of the $1940^{\text {th }}$ years: regional aspect]. St. Petersburg, St. Petersburg named V. B. Bobkov branch GKOU VPO "Russian Customs Academy", 2014, 208 p. (in Russian)

Kvartal'nye otchety o rabote OChO lagerei [Quarterly reports on the work of operative departments of NKVD-MVD in camps]. Gosudarstvennyi arkhiv Estonii, filial [State Archives of Estonia, branch], f. 17 SM, op. 8, d.38. (in Russian, unpablished)

Koloshinskaia N.V. Delo G. Remlingera i drugikh v kontekste poslevoennykh sudebnykh presledovanii nemetskikh voennoplennykh [Case G. Remlingera and others in the context of post-war German POWs prosecutions]. Istoriia gosudarstva i prava [History of State and Law], 2002, no. 1, pp. 28-33. (in Russian)

Lomagin N.A. Neizvestnaia blokada. Dokumenty i prilozheniia [Unknown blockade. Documents and applications]. Book 2. $2^{\text {nd }}$ ed. St. Petersburg, "Neva" Publ., 480 p. (in Russian)

Materialy priema-sdachi operativnogo otdela upravleniia lageria № 286 MVD ESSR [Materials reception and transmission of the operational department of the camp number 286 of the Estonian Ministry of Internal Affairs]. Gosudarstvennyi arkhiv Estonii, filial (ERAF) [State Archives of Estonia, branch], f. 9 ASM, op. 1, d. 50. (in Russian, unpablished)

Otchety po voennoplennym [Reports on Prisoners of War]. Gosudarstvennyi arkhiv Estonii, filial (ERAF) [State Archives of Estonia, branch], f. 17 SM, op. 8, d.12. (in Russian, unpablished)

Perepiska po agenture i poduchetnomu elementu OChO lageria № 135 [Correspondence concerning prisoners of war and secret service NKVD operative department of the camp N 135]. Gosudarstvennyi arkhiv Estonii, filial (ERAF) [State Archives of Estonia, branch], f.13 SM, op. 1, d.21. (in Russian, unpablished)

Spiski voennoplennykh-voennykh prestupnikov i spravki ob ikh deiatel'nosti [Lists of prisoners of war war criminals and information on their activities]. Gosudarstvennyi arkhiv Estonii, filial (ERAF) [State Archives of Estonia, branch], f. 13 SM, op. 1, d.20. (in Russian, unpablished)

Spravki i dokladnye zapiski lageria № 286 [Information and documents camp № 286]. Gosudarstvennyi arkhiv Estonii, filial (ERAF) [State Archives of Estonia, branch], f.17 SM, op. 8, d.7. (in Russian, unpablished)

Spravki i dokladnye zapiski lageria № 287 [Information and documents camp N 287]. Gosudarstvennyi arkhiv Estonii, filial (ERAF) [State Archives of Estonia, branch], f. 17 SM, op. 8, d. 8. (in Russian, unpablished)

Khodiakov M.V. "Ia nikogda ne stanu drugom Sovetskogo Soiuza": nastroeniia inostrannykh voennoplennykh v lageriakh NKVD-MVD vo vtoroi polovine $1940 \mathrm{kh}$ gg. ["I'll never be a friend of the Soviet Union": the mood of foreign prisoners in the camps of the NKVD-MVD in the second half of the 1940s. Peterburgskii istoricheskii zhurnal [Petersburg Historical Journal], 2014, no. 1, pp. 169-181. (in Russian)

For citation: Khodjakov M. V. Intelligence work of the NKVD-MVD in the camps for foreign prisoners of the Great Patriotic War. Vestnik of Saint-Petersburg University. Series 2. History, 2016, issue 2, pp. 139-149. DOI: $10.21638 / 11701 /$ spbu02.2016.211 